\title{
Echocardiography: A Window into Mitral Valve Repair
}

\author{
José Ribeiro Ricardo Fontes-Carvalho \\ Thorax and Circulation Unit, Cardiology Department, Gaia Hospital Center, Vila Nova de Gaia, Portugal
}

Mitral valve regurgitation (MR) is common in the context of heart failure and is one of the most frequent indications for invasive treatment, either cardiac surgery or percutaneous intervention. Echocardiography plays a central role in the assessment of patient suitability for these procedures and is key in intervention planning, guidance, and follow-up. Primary evaluation is performed by transthoracic echocardiography (TTE). Transesophageal echocardiography (TEE) provides a more detailed approach, which can be useful for the prediction of outcomes and complications and in the setting of unclear TTE results, particularly if there are concerns regarding patient eligibility and intervention guidance [1].

Alain Carpentier radically changed the prognosis and clinical management of patients with MR by developing a novel surgical technique for mitral valve repair (MVr) [2]. Since then, 2-dimensional (2D) Doppler imaging and 3D echocardiography have both gained in relevance as they provide detailed imaging of the functional anatomy of the mitral valve (MV) and its dynamic structure. Today, an exhaustive echocardiographic study should always be the starting point when planning the treatment of patients with MR. Echocardiography represents "an unbreakable link" [3] and can provide precise data on the type and extent of valve lesions, the regurgitation mechanism, MR etiology and severity, and the capacity for repair $[4,5]$.

\section{KARGER}

() 2020 S. Karger AG, Basel

E-Mail karger@karger.com

www.karger.com/crd
There are different methods for repairing the MV, but the unifying principles include a comprehensive understanding of valve pathology, correction of leaflet coaptation, and reduction of annular dilatation [6]. Most importantly, the use of real-time echocardiography is essential to ensure optimal results, avoiding complications such as valvular incompetence, leakage, or systolic anterior movement, and thereby ensuring a durable repair.

For successful surgical and percutaneous MVr in secondary MR, accurate left ventricle (LV) assessment is mandatory, including LV volume, LV ejection fraction, and sphericity index, accompanied by geometric assessment of the MV apparatus (tenting area, coaptation depth, leaflet angles, and interpapillary muscle distance). TTE and TEE are the primary modalities, although detailed information can also be obtained with computed tomography and magnetic resonance imaging (MRI) [7].

Severe untreated MR has a fairly poor prognosis regardless of etiology $[8,9]$. Surgical treatment remains the first-line therapy for symptomatic and severe MR, especially for patients with a primary etiology. However, open-heart surgery is withheld in a high proportion of MR patients, mainly due to advanced age, diminished LV function, and comorbidities. Thus, percutaneous treatment options have been recently developed as an alternative [10]. Two recent trials of transcatheter MVr place-

Jose Manuel Coelho Ribeiro

Cardiology Department, Gaia General Hospital Center

Rua Conceição Fernandes

PT-4434-502 Vila Nova de Gaia, Porto (Portugal)

E-Mail cardiogaia@gmail.com 
ment of MitraClip ${ }^{\circledR}$ in patients with functional MR (FMR) showed different results when compared with medical therapy only, with respect to all-cause mortality and the rate of hospitalization for heart failure [11]. The rationale for the conflicting results includes the echocardiographic parameters used and the FMR classification. Assessing MV dysfunction in these studies feels like opening a Pandora's box because they used different echocardiographic methodologies [12]. Traditional approaches to the characterization of secondary or FMR have largely ignored the critical importance of the LV [13]. The critical question distinguishing valvular from ventricular contributions to MR is not whether a lesion is "primary" or "secondary," but whether the magnitude of MR can be explained by the degree of LV dilatation. In patients with severe MR and impaired systolic function, the terms "proportionate" and "disproportionate" help to identify which patients will benefit from medical treatments that target the LV or from transcatheter interventions that target the MV [14].

Surgical MVr is considered the gold standard treatment for chronic severe degenerative MR [9]. Transcatheter MVr technologies have lately emerged to offer an alternative option to conventional direct-access approaches based on the placement of e-PTFE sutures as replacement neochordae on a beating heart while using 2D and 3D TEE guidance, without the need for cardiopulmonary bypass [15]. In the near future, with the rapidly expanding field of catheter-based technologies, the additional application of multiple-device therapies (e.g., with annuloplasty devices) will increase the surgical armamentarium for MVr.

Evaluating the severity of regurgitant lesions is among the most difficult problems in valvular heart disease. It is recommended that echocardiography quantification of MR be performed with an integrated methodology that combines the anatomical and functional elements with a multiparametric flow assessment [9]. The evaluation of MR severity ideally combines multiple parameters because all methods have intrinsic limitations and lack precision. The optimal management of patients with MR requires excellent clinical judgment and imaging skills [5]. Imaging determines anatomical indication for a specific intervention, defines device sizing, and may predict procedure complications. To achieve this, the experience of the imaging specialist is of primary importance. Therefore, the development of guidelines regarding a structured imaging curriculum designed to meet the needs of cardiac surgery and percutaneous intervention is of the utmost importance [16-18].

The complex anatomy of the MV makes it a challenging structure for imaging studies. MR is not only linked to leaflet dysfunction and requires high performance from the echocardiographic techniques as a real-time imaging tool with $3 \mathrm{D}$ capability, enabling a complete and clinically integrated response. It is important to highlight that the information obtained by imaging may have a significant impact on outcomes, both on surgical or percutaneous valve repair. The experience of the operator and an imaging curriculum are required and can contribute to better outcomes.

\section{Disclosure Statement}

No potential conflicts of interest relevant to this article were reported.

\section{Funding Sources}

There was no external funding.

\section{References}

1 Douglas PS, et al. ACCF/ASE/ACEP/ASNC/ SCAI/SCCT/SCMR 2007 Appropriateness Criteria for Transthoracic and Transesophageal Echocardiography*. J Am Soc Echocardiogr. 2007;20:787-805.

2 Carpentier A. Cardiac valve surgery - the "French correction". J Thorac Cardiovasc Surg. 1983 Sep;86(3):323-37.

3 Cimino S. Echocardiography and correction of mitral regurgitation: an unbreakable link. 2019. In press.
4 Castillo JG, Solís J, González-Pinto A, Adams DH. Surgical echocardiography of the mitral valve. Rev Esp Cardiol. 2011;64(12):1169-81. Spanish.

5 Zoghbi WA, Adams D, Bonow RO, EnriquezSarano M, Foster E, Grayburn PA, et al. Recommendations for noninvasive evaluation of native valvular regurgitation: a report from the American Society of Echocardiography developed in collaboration with the Society for Cardiovascular Magnetic Resonance. Am Soc Echocardiogr. 2017 Apr;30(4):30371.
6 Schubert SA, Mehaffey JH, Charles EJ, Kron IL. Mitral valve repair: the French correction versus the American correction. Surg Clin North Am. 2017 Aug;97(4):867-88.

7 Podlesnikar T, Delgado V, Bax JJ. Imaging of valvular heart disease in heart failure. Card Fail Rev. 2018;4(2):78-86.

8 Senni M, Adamo M, Metra M, Alfieri O, Vahanian A. Treatment of functional mitral regurgitation in chronic heart failure: can we get a 'proof of concept' from the MITRA-FR and COAPT trials? Eur J Heart Fail. 2019;21(7): $1-10$. 
9 Falk V, et al. 2017 ESC/EACTS Guidelines for the management of valvular heart disease. Eur J Cardiothorac Surg. 2017 Oct 1;52(4):61664.

10 Tabata N, Sinning JM, Kaikita K, Tsujita K, Nickenig G, Werner N. Current status and future perspective of structural heart disease intervention. J Cardiol. 2019 Jul;74(1):1-12.

11 Pibarot P, Delgado V, Bax JJ. MITRA-FR vs. COAPT: lessons from two trials with diametrically opposed results. Eur Heart J Cardiovasc Imaging. 2019 Jun;20(6):620-624.

12 Hagendorff A, Doenst T, Falk V. Echocardiographic assessment of functional mitral regurgitation: opening Pandora's box? ESC Heart Fail. 2019 Aug;6(4):678-685.
13 Tang GH, Verma S, Bhatt DL. Two randomized clinical trials on the treatment of secondary mitral regurgitation - contradictory or complementary? JAMA Cardiol. 2019 Apr; 4(4):311-3.

14 Grayburn PA, Sannino A, Packer M. Proportionate and disproportionate functional mitral regurgitation: a new conceptual framework that reconciles the results of the MITRA-FR and COAPT trials. JACC Cardiovasc Imaging. 2019 Feb;12(2):353-62.

15 Colli A, et al. Transapical NeoChord mitral valve repair. Ann Cardiothorac Surg. 2018;7: $812-20$.
16 Wiegers SE, Ryan T, Arrighi JA, Brown SM, Canaday B, Damp JB, et al. 2019 ACC/AHA/ ASE Advanced Training Statement on Echocardiography (revision of the $2003 \mathrm{ACC} /$ AHA Clinical Competence Statement on Echocardiography): a report of the ACC Competency Management Committee. J Am Coll Cardiol. 2019 Jul;74(3):377-402.

17 Thaden JJ, Tsang MY, Ayoub C, Padang R, Nkomo VT, Tucker SF, et al. Association between echocardiography laboratory accreditation and the quality of imaging and reporting for valvular heart disease. Circ Cardiovasc Imaging. 2017 Aug; 10(8):1-11.

18 Faza NN, Özden Tok Ö, Hahn RT. Imaging in structural heart disease: the evolution of a new subspecialty. JACC Case Reports. 2019;1(3): 440-5. 